\title{
STRATEGI PENGEMBANGAN USAHA PERIKANAN TANGKAP DI KABUPATEN KAYONG UTARA
}

\section{Development Strategy on Capture Fisheries in District Kayong Utara}

\author{
${ }^{*}$ Risna Yusuf dan Rizky Muhartono \\ Balai Besar Riset Sosial Ekonomi Kelautan dan Perikanan \\ Gedung Balitbang KP I Lt. 4 \\ Jalan Pasir Putih Nomor 1 Ancol Timur, Jakarta Utara, Indonesia \\ Telp: (021) 64711583 Fax: 64700924 \\ Diterima tanggal: 15 Mei 2017 Diterima setelah perbaikan: 21 September 2017 \\ Disetujui terbit: 12 Desember 2017 \\ *email: risna.sujana@yahoo.com
}

\begin{abstract}
ABSTRAK
Kabupaten Kayong Utara masuk ke dalam WPP 711 dan memiliki 103 pulau yang tersebar di empat kecamatan. Selain potensi perikanan tangkap, kabupaten ini memiliki potensi perikanan perairan umum berupa sungai, rawa waduk dan budi daya kolam. Potensi yang dimiliki belum sepenuhnya dimanfaatkan secara optimal. Tujuan penelitian ini adalah untuk mengetahui langkah-langkah strategi yang akan dilakukan dalam rangka mengembangkan perikanan tangkap di Kabupaten Kayong Utara. Data yang dikumpulkan berupa data primer dan data sekunder yang berasal dari berbagai sumber informasi yang terkait dengan penelitian yang dilakukan. Metode analisis yang digunakan adalah metode SWOT dan QSPM. Hasil penelitian menunjukkan bahwa bahwa strategi yang perlu dilakukan untuk pengembangan perikanan tangkap di Kabupaten Kayong Utara yaitu; (1) Pengembangan teknologi penangkapan; (2) Peningkatan pengawasan terhadap wilayah penangkapan, dan; (3) Membangun sarana transportasi dan distribusi ikan. Adapun urutan prioritas langkah-langkah strategi dengan pendekatan QSPM adalah sebagai berikut; (1) Pengembangan teknologi penangkapan dengan total score attractiveness sebesar 18,33005694; (2) Membangun sarana transportasi dan distribusi ikan dengan total score attractiveness sebesar 13,13045483, dan; (3) Peningkatan pengawasan terhadap wilayah penangkapan dengan total score attractiveness sebesar 10,7027257. Pengembangan teknologi penangkapan dan armada bagi nelayan lokal diharapkan mampu meningkatkan produktivitas dalam melakukan kegiatan penangkapan sehingga mampu bersaing dengan nelayan pendatang yang melakukan kegiatan penangkapan di wilayah yang sama. Kegiatan pengawasan terhadap aktivitas penangkapan mutlak diperlukan guna mencegah penggunaan alat tangkap yang tidak ramah lingkungan. Wilayah yang luas dan memiliki pulau-pulau yang tersebar, mengharuskan dibangunnya sistem transportasi dan distribusi pengangkutan ikan yang efektif dan menguntungkan sehingga hasil tangkapan nelayan memiliki nilai jual yang baik dan mampu bersaing.
\end{abstract}

Kata Kunci: strategi, perikanan tangkap, SWOT, QSPM

\begin{abstract}
Kayong Utara Regency located at WPP 711 and have 103 island that spread into four district. Besides capture fisheries, this regency have potency in inland fisheries such as river, swamp, reservoir and pond aquaculture but in fact, it is not been fully utilized. The goal of the research was to identify the steps of strategy in order to develop of capture fisheries in District Kayong Utara. the research using primary and secondary data. The analysis data using SWOT and QSPM. The result showed that the strategy of developing capture fisheries in District Kayong Utara were (1) Developing capture technology; (2) Increasing of monitoring capture areas; (3) Buiding transportation vihecle and distribution. The priority of steps on the QSPM approach of strategy were (developing capture technology with the total score was 18,33005694; (2) Buiding of transportation and distribustion of fish the tottal score was 13,13045483; and (3) Increasing of supervision to fishing grounds with total attractiveness score 10,7027257. Development of capture technology and fleet to local fisher expected to be able increasing produktivity and can compete with andon fisher that conduct fishing activities in the same area. Supervision of fisheries must be done to prevent Illegal fishing. A wide area with most islands are scattered, require to be built transportation and distribution system, which the fishermen that has benefits, good selling point and able to compete.
\end{abstract}

Keywords: strategy, capture fisheries, SWOT, QSPM 


\section{PENDAHULUAN}

Kayong Utara merupakan salah satu kabupaten yang berada di Propinsi Kalimantan Barat yang berada di wilayah penangkapan di WPP (wilayah pengelolaan perikanan) 711. Di sebelah utara wilayah ini berbatasan dengan Kabupaten Pontianak, wilayah barat berbatasan dengan Laut Natuna, wilayah selatan dan Timur berbatasan dengan Kabupaten Ketapang. Kabupaten Kayong Utara memiliki 103 pulau yang tersebar di empat kecamatan yaitu Kecamatan Kepulauan Karimata (82 pulau), Simpang Hilir (2 pulau), Sukadana (9 pulau) dan Pulau Maya (10 pulau), sedangkan Kecamatan Seponti dan Teluk Batang tidak memiliki pulau-pulau.

Kabupaten Kayong Utara memiliki luas wilayah laut $10.380 \mathrm{~km}^{2}$ yang tersebar di lima kecamatan dengan luasan terbesar pada Kecamatan Kepulauan Karimata $7.200 \mathrm{~km}^{2}$ dan Kecamatan Pulau Maya $2.544 \mathrm{~km}^{2}$, tiga kecamatan lainnya memiliki luasan laut berkisar $96-282 \mathrm{~km}^{2}$, sedangkan Kecamatan Seponti tidak memiliki laut. Kabupaten ini memiliki wilayah perairan umum berupa sungai $(2.550 \mathrm{Ha})$ yang tersebar di lima kecamatan, rawa tersebar di lima kecamatan (142 Ha) dan danau tersebar di dua kecamatan (2 Ha). Kecamatan yang tidak memiliki sungai dan rawa adalah Kecamatan Kepulauan Karimata dan kecamatan yang memiliki danau adalah Kecamatan Pulau Maya dan Simpang Hilir. Selain itu, Kabupaten Kayong Utara juga memiliki budi daya kolam sebesar $6.500 \mathrm{Ha}$ (lima kecamatan), tambak $5.750 \mathrm{Ha}$ (empat kecamatan) dan budi daya laut di 11 Lokasi (Kecamatan Pulau Maya dan Kecamatan Kepulauan Karimata).

Produksi perikanan kabupaten Kayong Utara tahun 2014 mencapai 25.612,7 ton dengan perincian total tangkapan perikanan laut mencapai $24.585,90$ ton, perikanan perairan umum 710,50 ton dan budi daya kolam 316,30 ton (Kayong Utara dalam angka 2015). Potensi perikanan tangkap di Kabupaten Kayong Utara tersebar di lima kecamatan dan terpusat wilayah di perairan Selat Karimata yang masuk wilayah Kecamatan Pulau Maya dan Kepulauan Karimata. Nelayan Kabupaten Kayong Utara umumnya nelayan tradisional, yang menggunakan perahu dengan ukuran <10 GT. Nelayan ini biasa melakukan penangkapan ikan dengan lokasi yang tidak terlalu jauh dari perairan pantai.
Potensi perikanan di Kabupaten Kayong Utara yang besar ini belum sepenuhnya dimanfaatkan secara optimal dikarenakan masih rendahnya ketersediaan sarana dan prasarana penanganan hasil tangkapan (RPJD 2008-2025). Informasi ini sejalan dengan hasil observasi dan wawancara di lapang yang dilakukan pada tahun 2016, bahwa teknologi penangkapan nelayan lokal masih belum mampu bersaing dengan nelayan yang datang dari luar daerah dan produk olahan masih skala tradisional. Tulisan ini bertujuan mengetahui langkah-langkah strategi yang akan dilakukan dalam rangka mengembangkan perikanan tangkap di Kabupaten Kayong Utara. sehingga pemerintah dapat mengambil langkahlangkah strategi alam upaya pengembangan usaha perikanan tangkap khususnya perikanan tangkap yang ada di Kabupaten Kayong Utara.

\section{METODOLOGI}

\section{Jenis dan Sumber Data}

Data yang dikumpulkan berupa data primer dan data sekunder. Data sekunder terkait dengan berbagai kebijakan produksi, jumlah produksi, sedangkan data primer meliputi data-data persepsi para stakeholder terkait dengan pengembangan bisnis perikanan tangkap di Kabupaten Kayong Utara-Kalimantan Barat.

\section{Teknik Pengumpulan Data.}

Data diperoleh dari informan kunci yang berasal dari berbagai stakeholder yang terkait dalam pengembangan perikanan di Kabupaten Kayong Utara yaitu dinas Kelautan dan Perikanan, Bappeda, Dinas Perindustrian dan Perdagangan, Dinas Pariwisata, pelaku usaha perikanan. Data dikumpulkan dengan teknik wawancara dengan menggunakan kuesioner terkait dengan potensi dan permasalahan, peluang dan tantangan dalam usaha perikanan tangkap di Kabupaten Kayong Utara-Kalimantan Barat.

\section{Metode Analisis Data}

Analisis data dalam penelitian ini adalah analisis kuantitatif yang dilakukan dengan menggunakan analisis SWOT. Analisis ini dilakukan untuk mengidentifikasi berbagai faktor secara sistematis dalam rangka penyusunan strategi dan kebijakan yang akan dipilih. Analisis ini berbasis pada cara berpikir logis dalam memaksimalkan 
kekuatan (Strength) dan peluang (Opportunities) serta minimalisasi kelemahan (Weaknesses) dan ancaman (Threats) (Rangkuti, 2002).

Penelitian yang menggunakan analisa SWOT dan QSPM diantaranya: Zulkarnaen dan Sutopo (2013) tentang strategi pemasaran UKM; Mahfud et al. (2017) tentang Strategi Peningkatan Mutu Lulusan Program Studi Tata Boga; Setyorini et al. (2016) Strategi pemasaran restauran; David, Meredith et al. (2009) tentang strategi Penjualan komputer; Puspitasari et al. (2013) tentang strategi bisnis industri gerabah; Zulkarnaen (2013) tentang strategi pemasaran UKM; Ghosiyan dan Sutopo (2015) tentang strategi pengembangan olah raga; dan Purwandari (2015) tentang Strategi pemasaran SMK.

Proses implementasi SWOT diawali dengan: (a) tahapan identifikasi data dan informasi sebagai bahan evaluasi faktor internal dan eksternal; (b) tahapan analisis melalui pemetaan faktor-faktor teridentifikasi dalam bentuk matrik SWOT; (c) tahapan pengambilan keputusan berdasarkan pada tahapan (a) dan (b). Secara garis besar SWOT mengilustrasikan secara jelas bagaimana peluang dan ancaman yang dihadapi untuk mencapai tujuan, disesuaikan dengan kekuatan dan kelemahan yang dimiliki sehingga dapat dirumuskan strategi dan kebijakan antisipasinya seperti digambarkan pada Tabel 1.
Penerapan Quantitative Strategic Planning Matrix (QSPM) diawali dengan menentukan faktorfaktor kunci dari suatu strategi melalui hasil analisis SWOT. Selanjutnya, masing-masing strategi diberikan pembobotan dan disajikan dalam bentuk matriks. Berdasarkan matriks tersebut, responden yaitu para stakeholder akan diminta untuk memberikan nilai numerik 1-5 mengikuti skala Likert, kemudian hasil pembobotan menurut faktorfaktor kunci pilihan strategi yang telah teridentifikasi dikalikan dengan hasil penilai panel ahli dan hasil akhir perkalian diurutkan; nilai tertinggi bobot akhir merepresentsikan prioritas pilihan strategi.

\section{HASIL DAN PEMBAHASAN}

\section{Deskripsi Perikanan di Kabupaten Kayong Utara}

Pada Tabel 2 dapat dilihat sebaran produksi perikanan di Kabupaten Kayong Utara berdasarkan kecamatan. Produksi perikanan laut terbanyak ada pada kecamatan Pulau Maya (11.411 ton) dan Kecamatan Kepulauan Karimata (8.114,30 ton). Pada tipologi perairan umum, kecamatan dengan jumlah produksi terbesar adalah Kecamatan Simpang Hilir (618,60 ton), sedangkan produksi budi daya kolam terbesar ada pada Kecamatan Pulau Maya (198,10 ton).

Tabel 1. Kerangka Matriks SWOT Pengembangan Usaha Perikanan Tangkap .

Table 1. Framework of SWOT Matrix of Capture Fishery Business Development.

\begin{tabular}{|c|c|c|}
\hline Ekctarnal & Kekuatan (S)/ Strengthen & Kelemahan (W)/ Weakness \\
\hline \multirow[b]{2}{*}{ Peluang/ Opportunity (0) } & Strategi SO/ SO Strategy & Strategi WO/ WO Strategy \\
\hline & $\begin{array}{l}\text { Strategi ini dirumuskan dengan tujuan } \\
\text { memaksimalkan kekuatan untuk } \\
\text { memanfaatkan peluang/ This strategy is } \\
\text { formulated with the goal of maximizing } \\
\text { the power to exploit opportunities This } \\
\text { strategy is formulated with the objective } \\
\text { of minimizing weaknesses to exploit } \\
\text { opportunities }\end{array}$ & $\begin{array}{l}\text { Strategi ini dirumuskan dengan } \\
\text { tujuan meminimalkan kelemahan } \\
\text { untuk memanfaatkan peluang/ } \\
\text { This strategy is formulated } \\
\text { with the aim of minimizing } \\
\text { weaknesses to take advantage of } \\
\text { opportunities }\end{array}$ \\
\hline \multirow[b]{2}{*}{ Ancaman (T)/ Threat } & Strategi ST/ ST Strategy & Strategi WT/ WT Strategy \\
\hline & $\begin{array}{l}\text { Strategi ini dirumuskan dengan tujuan } \\
\text { menggunakan kekuatan yang ada untuk } \\
\text { mengatasi ancaman/ This strategy is } \\
\text { formulated with the aim of using existing } \\
\text { powers to address threats }\end{array}$ & $\begin{array}{l}\text { Strategi ini dirumuskan dengan } \\
\text { tujuan meminimalkan kelemahan } \\
\text { dan menghindari ancaman/ } \\
\text { This strategy is formulated with } \\
\text { the objective of minimizing } \\
\text { weaknesses and avoiding threats }\end{array}$ \\
\hline
\end{tabular}


Tabel 2 Produksi Perikanan (Ton) Menurut Kecamatan 2014.

Table 2. Fishery Productioan (ton) by District, 2014.

\begin{tabular}{lrrr}
\hline Kecamatan/District & Laut/Ocean & $\begin{array}{c}\text { Perairan Umum/ } \\
\text { General Water }\end{array}$ & $\begin{array}{c}\text { Budi Daya Kolam/ } \\
\text { Pond Cultivation }\end{array}$ \\
\hline Pulau Maya & 11,411 & 6.10 & 198.10 \\
Sukadana & 2,131 & 41 & 69.40 \\
Simpang Hilir & $1,812.1$ & 618.60 & 10.10 \\
Teluk Batang & $1,117.50$ & 11.30 & 4.30 \\
Seponti & - & 32.90 & 1.90 \\
Kepulauan Karimata & $8,114.30$ & 0.60 & 32.50 \\
\hline Jumlah/Total & $\mathbf{2 4 , 5 8 5 . 9 0}$ & $\mathbf{7 1 0 . 5 0}$ & $\mathbf{3 1 6 . 3 0}$ \\
\hline
\end{tabular}

Sumber: Kabupaten Kayong Dalam Angka, 2015/ Source: Kayong District In Figures, 2015

Pada tabel 3 dapat dilihat bahwa jumlah nelayan terbesar ada pada Kecamatan Pulau Maya (2.552 orang) dan Kepulauan Karimata (1.068 orang). Demikian halnya dengan unit penangkap ikan, armada tanpa motor dan kapal motor terbanyak ada di Kecamatan Pulau Maya (154 unit) dan 251 unit, sedangkan armada motor tempel terbanyak ada pada kecamatan Pulau Maya (187 unit) dan Kecamatan Kepulauan Karimata (174 unit). Berdasarkan data statistik perikanan tangkap Kabupaten Kayong Utara, hampir 85\% RTP didominasi oleh armada perikanan kecil ( $\leq 5 \mathrm{GT}$ ), dengan daerah penangkapan ikan lebih dominan di wilayah pengelolaan kabupaten/kota yang berjarak paling jauh sekitar 4 mil dari pantai.

Pada Tabel 4 dapat dilihat bahwa alat tangkap jaring insang tetap, rawai dan jaring jala lainnya, merupakan alat tangkap yang ditemui di semua kecamatan. Jaring insang tetap mayoritas ditemui di Kecamatan Teluk Batang, sedangkan jaring insang tetap dan rawai mayoritas ditemui di Kecamatan Pulau Maya. Alat tangkap Jaring lingkar dan serok hanya ditemui di Kecamatan
Pulau Maya, sedangkan bagan tancap dan bubu hanya ditemui di Kecamatan Kepulauan Karimata.

Penggunaan alat tangkap nelayan berbeda disesuaikan dengan keahlian/kebiasaan, kemampuan membeli, lokasi tangkapan, dan musim. Mayoritas nelayan di Kecamatan Pulau Maya menggunakan tramel nel (200 unit). Nelayan di Kecamatan Sukadana, Simpang Hilir, dan Kepulauan Karimata mayoritas menggunakan jaring insang tetap dengan rincian 71 unit, 63 unit dan 106 unit. Sedangkan Kecamatan Teluk Batang dan Seponti, mayoritas menggunakan Jala jaring lainnya (60 dan 30 unit).

Pada saat dilakukan FGD (focus group discussion) muncul beberapa isu dan permasalahan yang masih ditemui nelayan dan dirasakan menjadi kendala pada kegiatan penangkapan (Tabel 5). Isu dan permasalahan tersebut yaitu: penangkapan kapal dari luar, alat tangkap tidak ramah lingkungan (trawl), lembaga permodalan, SPDN, armada skala kecil, darmaga labuh di pulau-pulau, pasokan es, penangkapan kapal dari Luar.

Tabel 3 Jumlah Nelayan dan Unit Penangkapan Ikan,2014.

Table 3. Number of Fishers and Water Fishery Unit, 2014.

\begin{tabular}{lcccc}
\hline \multirow{2}{*}{$\begin{array}{c}\text { Kecamatan/ } \\
\text { District }\end{array}$} & $\begin{array}{c}\text { Jumlah Nelayan/ } \\
\text { Total Fishers }\end{array}$ & $\begin{array}{c}\text { Tanpa Motor/ } \\
\text { Without Motor }\end{array}$ & $\begin{array}{c}\text { Motor Tempel/ } \\
\text { Attached Motor }\end{array}$ & $\begin{array}{c}\text { Kapal motorl } \\
\text { Motor Boat }\end{array}$ \\
\cline { 3 - 5 } Pulau Maya & 2,552 & 154 & 187 & 251 \\
Sukadana & 240 & 74 & 7 & 23 \\
Simpang Hilir & 541 & 53 & 63 & 23 \\
Teluk Batang & 247 & 36 & 32 & 11 \\
Seponti & 32 & 25 & 11 & - \\
Kepulauan Karimata & 1,068 & 80 & 174 & $\mathbf{3 9}$ \\
\hline Jumlah/Total & $\mathbf{4 , 6 8 0}$ & $\mathbf{4 2 2}$ & $\mathbf{4 7 4}$ & 36 \\
\hline
\end{tabular}

Sumber: Kabupaten Kayong Dalam Angka, 2015/Source:Kayong District In Figures, 2015 
Tabel 4. Jumlah Alat Penangkap Ikan Berdasarkan Kecamatan, 2014.

Table 4. Number of Catch Equipment by District, 2014.

\begin{tabular}{|c|c|c|c|c|c|c|}
\hline \multirow{2}{*}{$\begin{array}{l}\text { Alat Penangkap Ikan/ } \\
\text { Catch Equipment }\end{array}$} & \multicolumn{6}{|c|}{ Kecamatan/District } \\
\hline & Pulau Maya & Sukadana & $\begin{array}{l}\text { Simpang } \\
\text { Hilir }\end{array}$ & $\begin{array}{c}\text { Teluk } \\
\text { Batang }\end{array}$ & Seponti & $\begin{array}{c}\text { Kep. } \\
\text { Karimata }\end{array}$ \\
\hline Jaring pantai & 50 & 15 & 23 & 8 & - & - \\
\hline Jaring insang hanyut & - & 7 & 18 & - & - & 8 \\
\hline Jaring Lingkar & 36 & - & - & - & - & - \\
\hline Jaring Insang Tetap & 125 & 71 & 63 & 25 & 1 & 106 \\
\hline Tramel net & 200 & 24 & 27 & 13 & - & - \\
\hline Bagan Tancap & - & - & - & - & - & 53 \\
\hline Serok & 60 & - & - & - & - & - \\
\hline Jala Jaring lainnya & 18 & 22 & 25 & 60 & 30 & 20 \\
\hline Rawai & 50 & 36 & 27 & 16 & 5 & 65 \\
\hline Pancing Tonda & 2 & - & - & - & - & 23 \\
\hline Jermal/Togo & 40 & - & 15 & - & - & - \\
\hline Bubu & - & - & - & - & - & 45 \\
\hline $\begin{array}{l}\text { Penangkap Lainnya/ } \\
\text { Other Catch }\end{array}$ & 18 & - & 11 & 6 & - & 12 \\
\hline Jumlah/Total & 599 & 175 & 209 & 128 & 36 & 332 \\
\hline
\end{tabular}

Sumber: Kabupaten Kayong Dalam Angka, 2015/Source: Kayong District In Figures, 2015

Tabel 5. Isu dan Permasalahan pada Kegiatan Perikanan Tangkap, Kayong Utara 2016.

Table 5. Catch Fisheries Problems and Isue, Kayong Utara 2016.

\begin{tabular}{|c|c|}
\hline $\begin{array}{l}\text { Isu dan Permasalah/ } \\
\text { Problems and Issue }\end{array}$ & Keterangan/ Description \\
\hline $\begin{array}{l}\text { Penangkapan Kapal dari Luar/ } \\
\text { Catching of Ships from Outside }\end{array}$ & $\begin{array}{l}\text { Masih banyak ditemui kapal-kapal dari daerah lain yang melakukan kegiatan } \\
\text { penangkapan di lokasi tangkapan nelayan lokal/ There are still many ships from } \\
\text { other areas doing fishing activities at the local fishing grounds. }\end{array}$ \\
\hline $\begin{array}{l}\text { Alat tangkap tidak ramah } \\
\text { lingkungan (trawl)/ Unsustainable } \\
\text { fishing gear (trawling) }\end{array}$ & $\begin{array}{l}\text { Dicurigai masih ada penggunaan alat tangkap tidak ramah lingkungan } \\
\text { yang digunakan oleh nelayan dari daerah lain yang melakukan kegiatan } \\
\text { penangkapan/Suspected there is still the use of environmentally unfriendly } \\
\text { fishing gear used by fishermen from other areas that do fishing activities }\end{array}$ \\
\hline $\begin{array}{l}\text { Lembaga Permodalan/ / Capital } \\
\text { Institution }\end{array}$ & $\begin{array}{l}\text { Jumlah lembaga permodalan dirasakan masih sedikit dan belum berfungsi } \\
\text { sesuai dengan harapan nelayan/The number of capital institutions is still } \\
\text { small and not functioning in accordance with the expectations of fishermen. }\end{array}$ \\
\hline $\begin{array}{l}\text { SPDN/Solar Packed Dealer } \\
\text { Nelayan/ SPDN / Solar Packed } \\
\text { Dealers Fishermen }\end{array}$ & $\begin{array}{l}\text { Belum ada SPDN sehingga nelayan membeli secara eceran dengan harga } \\
\text { beli yang lebih tinggi/ There is no SPDN so fishermen buy at retail with higher } \\
\text { price. }\end{array}$ \\
\hline $\begin{array}{l}\text { Armada skala kecil/ Small-scale } \\
\text { fleet }\end{array}$ & $\begin{array}{l}\text { Jika dibandingkan dengan nelayan pendatang, nelayan lokal sebagian besar } \\
\text { menggunakan armada yang lebih kecil dan teknologi penangkapan yang kalah } \\
\text { bersaing/ In comparison with outsider fishermen, local fishermen mostly use } \\
\text { smaller fleets and less competitive fishing technology }\end{array}$ \\
\hline $\begin{array}{l}\text { Darmaga labuh di pulau-pulau/ } \\
\text { Darmaga flocking on the islands }\end{array}$ & $\begin{array}{l}\text { Jumlah darmaga labuh di lokasi pulau-pulau masih terbatas sehingga } \\
\text { menyulitkan nelayan pada saat melakukan sandar labuh kapal terutama pada } \\
\text { saat pasang-surut/ The number of darmaga flocking in the location of the } \\
\text { islands is still limited, making lead it difficult for fishermen during the boat dock, } \\
\text { especially at high tide. }\end{array}$ \\
\hline Pasokan es / Ice supply & $\begin{array}{l}\text { Produksi es terbatas, pabrik es belum menjangkau lokasi yang terpencil. } \\
\text { Nelayan menggunakan es rumah tangga dan es yang dipasok dari luar daerah/ } \\
\text { Ice production is limited, ice factory has not yet reached a remote location area. } \\
\text { Fishermen use household ice and ice supplied from outside the region }\end{array}$ \\
\hline
\end{tabular}

Sumber: Fokus Grup Diskusi 1 Juni 2016/Source: Focus Group Discussion 1 June 2016 


\section{Strategi Pengembangan Usaha Perikanan Tangkap di Kabupaten Kayong Utara}

Berdasarkan isu dan permasalahan pada tabel 5, dilakukan srategi pengembangan usaha perikanan tangkap dengan mempertimbangkan faktor kelemahan, kekuatan, peluang dan ancaman. Bagaimana kekuatan (strengths) mampu mengambil keuntungan (advantage) dari peluang (opportunities) yang ada, bagaimana cara mengatasi kelemahan (weaknesses) yang mencegah keuntungan (advantage) dan peluang (opportunities) yang ada, selanjutnya bagaimana kekuatan (strengths) mampu menghadapi ancaman (threats) yang ada, dan cara mengatasi kelemahan (weaknesses).

\section{Analisis Faktor Internal Strategis} Pengembangan Usaha Perikanan

Faktor internal pengembangan usaha perikanan dalam analisis SWOT terdiri dari faktor kekuatan (strenghts factors) dan faktor kelemahan (weakness factors) sebagai berikut:

1. Faktor kekuatan (strenghts factors) dalam penelitian ini merupakan suatu keunggulan yang dimiliki oleh perikanan tangkap dari hulu sampai hilir di Kayong Utara yang diidentifikasi sebagai berikut: (a) Potensi sumber daya perairan Indonesia; (b) wilayah penangkapan ikan; (c) akses distribusi ikan, dan; (d) jumlah kapal angkut.

2. Faktor kelemahan (weakness factors) dalam penelitian ini merupakan suatu keterbatasan atau kekurangan yang dianggap serius menghalangi kinerja pengembangan usaha perikanan tangkap di Kayong Utara yang diidentifikasi meliputi: (a) Alat tangkap tidak ramah lingkungan; (b) Jumlah armada skala kecil; (c) Ukuran armada skala kecil, dan; (d) Kapal lokal kalah bersaing dengan kapal pendatang.

Berdasarkan identifikasi faktor internal strategis, yang selanjutnya dilakukan penilaian bobot, rating dan skor terhadap setiap faktor yang teridentifikasi pada komponen kekuatan (S) dan komponen kelamahan (W) masing-masing sebesar 3,11 dan 0,49 atau untuk keseluruhan (agregat) dari faktor internal strategis adalah sebesar 3,598. Secara rinci penghitungan tersebut tertera pada Tabel 6.

Analisis Faktor Eksternal Strategis Pengembangan Usaha Perikanan

Faktor eksternal strategis dalam analisis SWOT terdiri dari faktor peluang (opportunities factors) dan faktor ancaman (threats factors) sebagai berikut:

Tabel 6. Hasil Analisis Faktor Internal Strategis dalam Pengembangan Usaha Perikanan Tangkap di Kayong Utara.

Table 6. The Result of Strategic Internal Factor Analysis in The Development of Capture Fishery Business in North Kayong.

\begin{tabular}{|c|c|c|c|c|}
\hline Faktor Internal/Internal Factor & Bobot & Rate & Skor & Total \\
\hline \multicolumn{5}{|l|}{ Kekuatan (Strenght-S)/Strengthen } \\
\hline $\begin{array}{l}\text { Potensi sumber daya perairan Indonesia/Potential of Indonesian } \\
\text { waters resources }\end{array}$ & 0.31 & 4.26 & 1.34 & 5.70 \\
\hline Wilayah penangkapan ikan/Fishing area & 0.26 & 3.84 & 1.01 & 3.88 \\
\hline Akses distribusi ikan/Access distribution of fish & 0.12 & 3.47 & 0.42 & 1.45 \\
\hline Jumlah Kapal angkut/Number of ships & 0.11 & 3.11 & 0.35 & 1.08 \\
\hline Jumlah/Total & 0.81 & 14.68 & 3.11 & 12.11 \\
\hline Faktor Internal/Internal Factor & Bobot & Rate & Skor & Total \\
\hline \multicolumn{5}{|l|}{ Kelemahan (Weakness -W)/Weakness } \\
\hline Alat tangkap tidak ramah lingkungan/Unsustainable fishing gear & 0.07 & 2.32 & 0.16 & 0.36 \\
\hline Jumlah Armada skala kecil/The number of small-scale fleet & 0.06 & 3.37 & 0.21 & 0.69 \\
\hline Ukuran Armada skala kecil/Small size fleet size & 0.05 & 2.00 & 0.10 & 0.21 \\
\hline $\begin{array}{l}\text { Kapal lokal kalah bersaing dengan kapal pendatang/Local vessels } \\
\text { are unable to compete with outsiders }\end{array}$ & 0.01 & 1.89 & 0.02 & 0.04 \\
\hline Jumlah/Total & 0.19 & 9.58 & 0.49 & 1.30 \\
\hline
\end{tabular}

Sumber:diolah dari data primer/Source:processed primary data 
1. Faktor peluang (opportunities factors), yaitu kesempatan atau peluang sumber daya yang dimiliki oleh perikanan tangkap di Kabupaten Kayong Utara yang diidentifikasi sebagai berikut: (a) Pembangunan pabrik es; (b) Keberadaan SPDN di pelabuhan, dan; (c) Pembangunan dermaga di pulau

2. Faktor ancaman (threats factors), yaitu suatu kondisi yang bersumber dari luar dan berpotensi memperlemah kinerja pengembangan usaha perikanan tangkap di Kayong Utara yang diidentifikasi sebagai berikut: (a) Akses terhadap kelembagaan permodalan; (b) Konflik dengan nelayan luar, dan; (c) Regulasi terkait dengan perijinan

Sebagaimana yang dilakukan dalam menghitung bobot, rating dan skor faktor internal strategis, maka berdasarkan identifikasi faktor eksternal strategis, dapat diketahui bahwa skor komposit untuk komponen peluang $(\mathrm{O})$ sebesar 2,84 dan untuk komponen ancaman ( $\mathrm{T}$ ) sebesar 8,86 , atau untuk keseluruhan (agregat) dari faktor eksternal strategis adalah sebesar 3,70531 . Secara rinci penghitungan tersebut tertera pada Tabel 7 .
Penentuan Strategi Pengembangan usaha perikanan tangkap di Kayong Utara

Berdasarkan hasi analisis faktor internal strategis (IFAS) dan faktor eksternal strategis (EFAS) serta perumusan alternatif strategi, ditentukan strategi yang dipilih adalah strategi SO, hal ini karena skor yang diperoleh didominasi oleh komponen faktor kekuatan (S) dan peluang (O). Dengan demikian dapat dikatakan bahwa strategi pengembangan usaha perikanan tangkap di Kayong Utara adalah Strategi SO. Peta penentuan strategi ini dapat dilihat pada Gambar 1.

Berdasarkan perumusan strategi dan perhitungan IFAS dan EFAS tersebut, maka strategi yang dapat ditempuh dalam pengembangan usaha perikanan tangkap di Kabupaten Kayong Utara adalah sebagai berikut:

(1) Pengembangan teknologi penangkapan

(2) Peningkatan pengawasan terhadap wilayah penangkapan

(3) Membangun sarana transportasi dan distribusi ikan

Tabel 7. Hasil Analisis Faktor Eksternal Strategis dalam Pengembangan Usaha Perikanan Tangkap di Kayong Utara Indonesia.

Table 7. Results of Strategic External Factor Analysis in The Development of Capture Fishery Enterprises in North Kayong Indonesia.

\begin{tabular}{|c|c|c|c|c|}
\hline Faktor Eksternal/External Factor & Bobot & Rate & Skor & Total \\
\hline \multicolumn{5}{|l|}{ Peluang (Opportunity-O)/ Opportunity (O) } \\
\hline $\begin{array}{l}\text { Pembangunan pabrik es/ The development of ice- } \\
\text { making factory }\end{array}$ & 0.22 & 4.05 & 0.90 & 3.66 \\
\hline $\begin{array}{l}\text { Keberadaan SPDN di pelabuhan/ The existence of } \\
\text { SPDN at the port }\end{array}$ & 0.32 & 3.84 & 1.23 & 4.74 \\
\hline $\begin{array}{l}\text { Pembangunan dermaga di Pulau/ The development } \\
\text { of the dock on the Island }\end{array}$ & 0.17 & 4.16 & 0.71 & 2.94 \\
\hline Jumlah/Total & 0.71 & 12.05 & 2.84 & 11.34 \\
\hline Faktor Eksternal/External Factor & Bobot & Rate & Skor & Total \\
\hline \multicolumn{5}{|l|}{ Ancaman (Treath-O)/ Threats (Treath-O) } \\
\hline $\begin{array}{l}\text { Akses terhadap kelembagaan permodalan/Access to } \\
\text { institutional capital }\end{array}$ & 0.15 & 3.53 & 0.52 & 1.85 \\
\hline $\begin{array}{l}\text { Konflik dengan nelayan luar/Conflict with outside } \\
\text { fishermen }\end{array}$ & 0.13 & 2.37 & 0.30 & 0.71 \\
\hline $\begin{array}{l}\text { Regulasi terkait dengan perijinan/Regulations related } \\
\text { to licensing }\end{array}$ & 0.01 & 3.58 & 0.04 & 0.13 \\
\hline Jumlah/Total & 0.29 & 9.47 & 0.86 & 2.69 \\
\hline
\end{tabular}

Sumber:diolah dari data primer/Source:processed primary data 


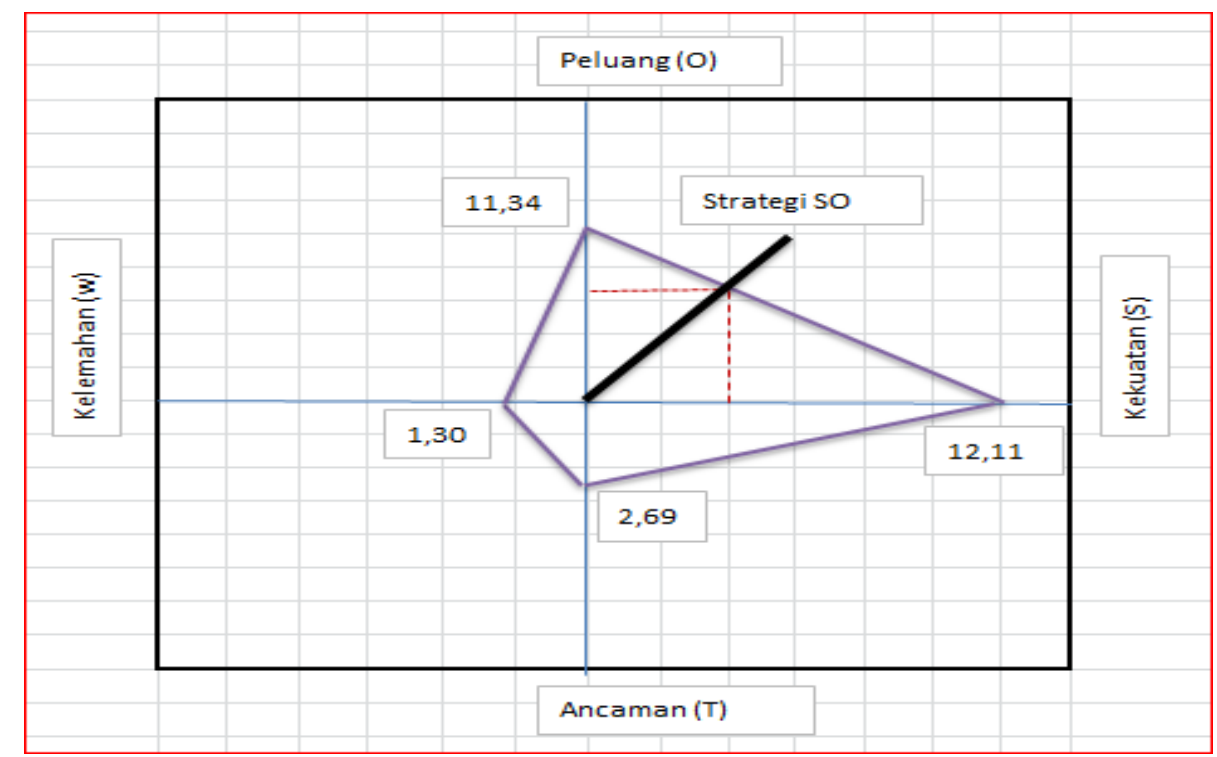

Gambar 1. Peta Strategi Pengembangan Usaha Perikanan Tangkap di Kayong Utara Indonesia. Figure 1. Map of Capture Fishery Business Development Strategy in North Kayong Indonesia.

Sumber: Hasil perhitungan data dan informasi dalam Tabel IFAS dan EFAS/

Source: Results of Data and Information Calculations in IFAS and EFAS Tables

Tabel 8. Perumusan Strategi Pengembangan usaha perikanan tangkap di Kayong Utara. Table 8. Formulation of Strategy of Capture Fishery Business Development in North Kayong.

\begin{tabular}{|c|c|c|}
\hline $\begin{array}{c}\text { Eksternal/ } \\
\text { External }\end{array}$ & $\begin{array}{l}\text { Kekuatan (Strength-S): } \\
\text { 1. Potensi sumber daya perairan } \\
\text { indonesia/Potential of Indonesian } \\
\text { waters resources } \\
\text { 2. Wilayah penangkapan ikan/ Fishing } \\
\text { areas } \\
\text { 2. Akses distribusi ikan/ Access } \\
\text { distribution of fish } \\
\text { 4. Jumlah Kapal angkut/Number of ships }\end{array}$ & $\begin{array}{l}\text { Kelemahan (Weakness-W) } \\
\text { 1. Alat tangkap tidak ramah } \\
\text { lingkungan/ Unsustainable } \\
\text { fishing gear } \\
\text { 2. Jumlah Armada skala kecil/ } \\
\text { The number of small-scale } \\
\text { fleet } \\
\text { 3. Ukuran Armada skala kecil/ } \\
\text { Small size fleet } \\
\text { 4. Kapal lokal kalah bersaing } \\
\text { dengan kapal pendatang/ } \\
\text { Local vessels are unable to } \\
\text { compete with outsiders }\end{array}$ \\
\hline Peluang (Opportunity-0): & Strateqi S-O: & \\
\hline $\begin{array}{l}\text { 1. Pembangunan Pabrik Es/The } \\
\text { development of ice-making factory } \\
\text { 2. Keberadaan SPDN di pelabuhan/ } \\
\text { The existence of SPDN at the port } \\
\text { 3. Pembangunan dermaga di pulau/ } \\
\text { The development of the dock on } \\
\text { the island }\end{array}$ & $\begin{array}{l}\text { 1. Pengembangan teknologi } \\
\text { penangkapan/Development of capture } \\
\text { technology } \\
\text { 2. Peningkatan pengawasan terhadap } \\
\text { wilayah penangkapan/Increased } \\
\text { supervision of fishing grounds } \\
\text { 3. Membangun sarana transportasi dan } \\
\text { distribusi ikan/ Build transportation } \\
\text { facilities and distribution of fish }\end{array}$ & Strategi $W-O$ : \\
\hline
\end{tabular}

\section{Ancaman (Threath-T)}

1. Akses terhadap kelembagaan permodalan/ Access to institutional capital

2. Konflik dengan nelayan luar/ Conflict with outside fishermen

3. Regulasi terkait dengan perijinan/ Regulations related to licensing

Sumber: Sintesa berdasarkan data dan informasi dalam Tabel IFAS dan EFAS/

Source: Synthesis based on data and information in IFAS and EFAS Table 


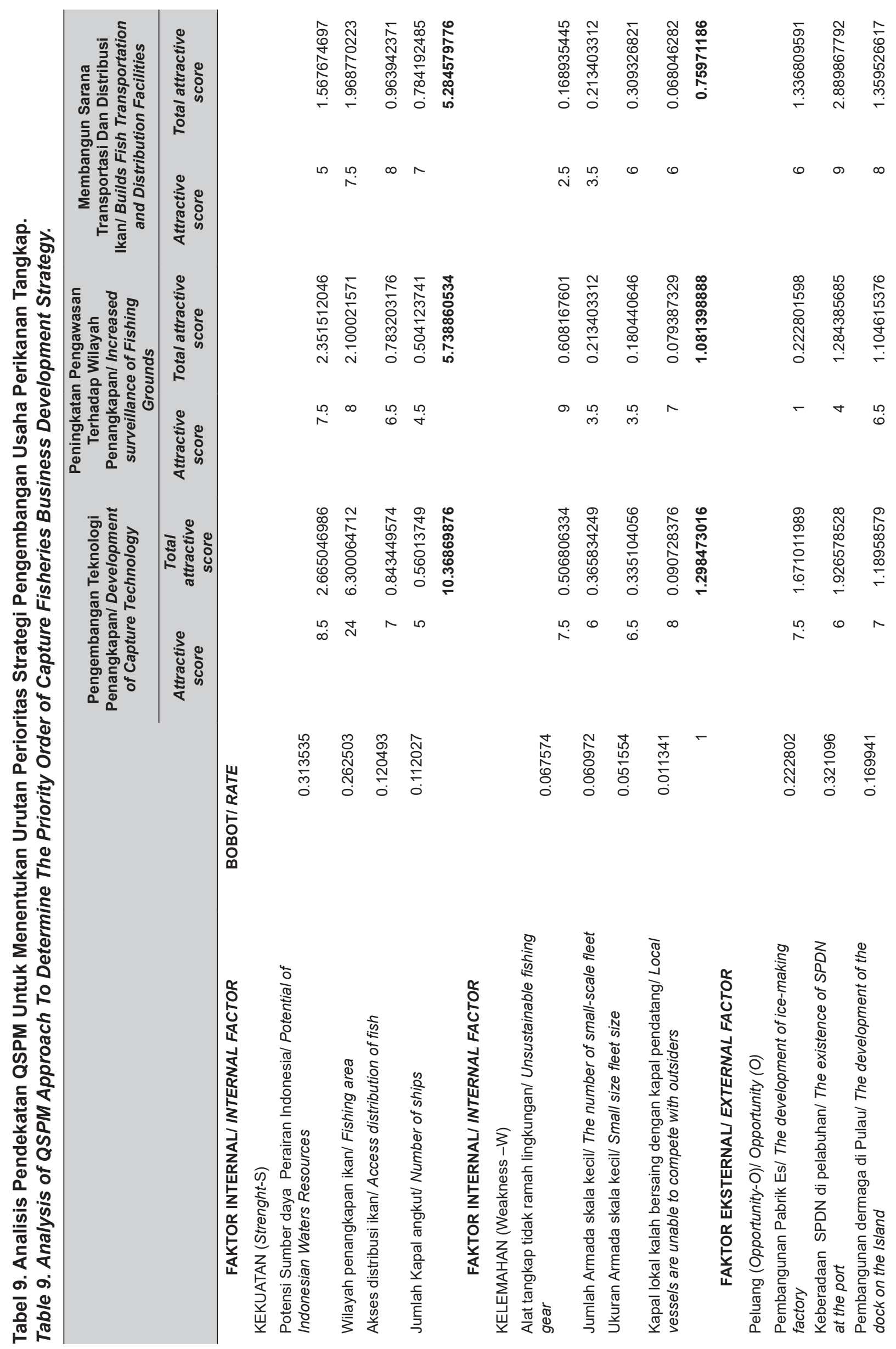




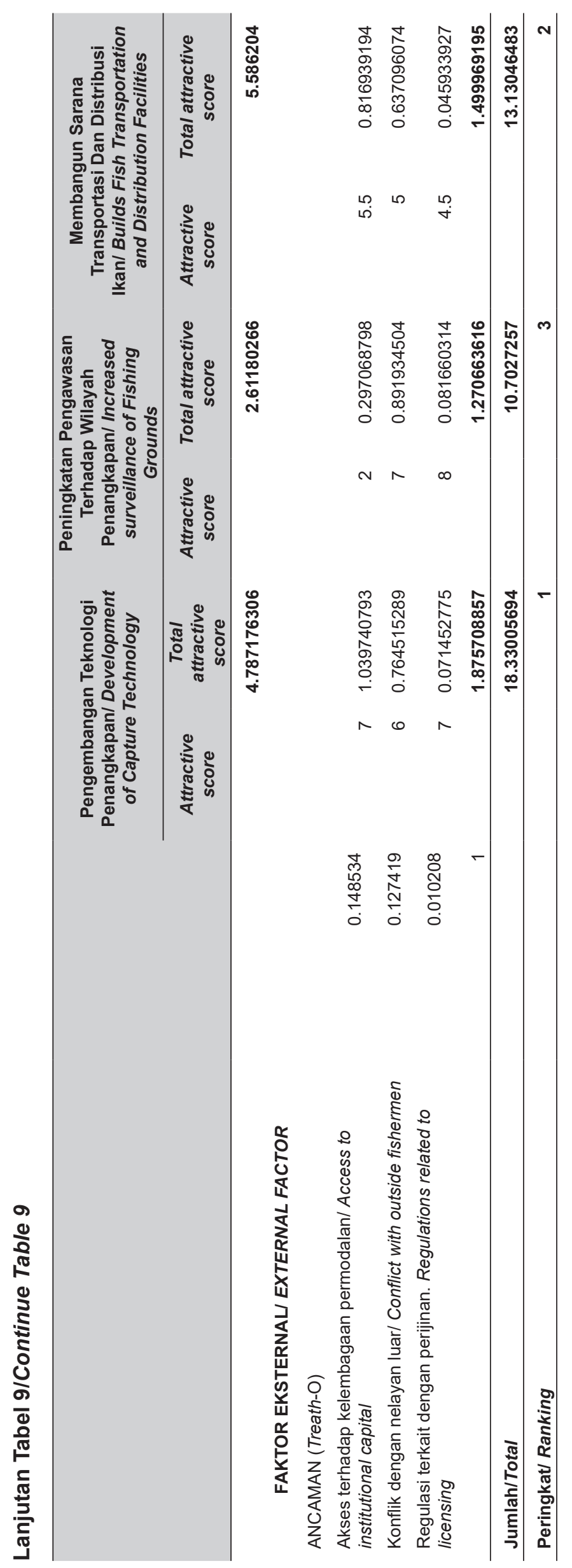




\section{Penentuan Perioritas Langkah-Langkah Strategi Pengembangan Usaha Perikanan Tangkap di Kabupaten Kayong Utara: Pendekatan QSPM}

Pengembangan usaha perikanan tangkap di Kayong Utara menggunakan model pendekatan. QSPM (Quantitatif Strategic Plan Matrix) dengan perioritas langkah-langkah strategi didominasi oleh komponen faktor kekuatan (S) dan peluang (O). Pada tabel 9 menyajikan hasil analisis pendekatan QSPM untuk menentukan urutan perioritas langkahlangkah strategi pengembangan usaha perikanan tangkap di Kabupaten Kayong Utara. Berdasarkan hasil analisis pada tabel tersebut ditemukan urutan perioritas langkah-langkah strategi tersebut adalah sebagai berikut:

(1) Pengembangan teknologi penangkapan dengan total score attractiveness sebesar 18,33005694 .

(2) Membangun sarana transportasi dan distribusi ikan dengan total score attractiveness sebesar 13,13045483.

(3) Peningkatan pengawasan terhadap wilayah penangkapan dengan total score attractiveness sebesar 10,7027257.

\section{KESIMPULAN DAN IMPLIKASI KEBIJAKAN}

\section{Kesimpulan}

Berdasarkan hasil perhitungan perumusan strategi danperhitungan IFAS dan EFAS, strategi yang dapat ditempuh dalam pengembangan usaha perikanan tangkap di Kabupaten Kayong Utara merupakan strategi yang didominasi faktor kekuatan (S) dan faktor peluang (O) adalah sebagai berikut: (1) pengembangan teknologi penangkapan; (2) peningkatan pengawasan terhadap wilayah penangkapan, dan; (3) pembangunan sarana transportasi dan distribusi ikan. Selanjutnya, urutan perioritas langkahlangkah strategi pengembangan usaha perikanan tangkap di Kabupaten Kayong Utara berdasarkan hasil analisis QSPM adalah sebagai berikut: (1) pengembangan teknologi penangkapan; (2) pembangunan sarana transportasi dan distribusi ikan, dan; (3) peningkatan pengawasan terhadap wilayah penangkapan.

\section{Implikasi Kebijakan}

Dalam rangka pengembangan usaha perikanan tangkap di Kabupaten Kayong Utara, perlu dilakukan upaya-upaya yang dapat meningkatkan usaha perikanan tangkap. Upayaupaya tersebut harus terkait dengan strategi dan kebijakan yang diberlakukan secara spesifik pada perikanan tangkap. Pengembangan teknologi penangkapan dan armada bagi nelayan lokal dengan melalui penambahan ukuran dan jumlah armada sehingga nelayan lokal diharapkan mampu meningkatkan produktivitas dalam melakukan kegiatan penangkapan sehingga nelayan lokal mampu bersaing dengan nelayan pendatang yang melakukan kegiatan penangkapan di wilayah yang sama.

Selanjutnya strategi terkait dengan pembangunan sistem transportasi dan distribusi ikan dengan melalui program peningkatan pembangunan pabrik es, dermaga di pulau dan SPDN di pelabuhan sehingga diharapkan sistem transportasi dan distribusi ikan dapat berjalan secara efektif dan efisien. Terakhir, dalam hal pengawasan terhadap wilayah penangkapan perlu adanya kebijakan terkait pemberian sanksi terhadap pelanggaran-pelanggaran yang dilakukan oleh nelayan-nelayan yang dalam kegiatan usahanya menggunakan alat tangkap yang tidak ramah lingkungan, sehingga diharapkan dengan kebijakan ini sumber daya ikan dan ekosistem laut dapat terjaga dengan baik.

\section{UCAPAN TERIMA KASIH}

Ucapan terima kasih disampaikan kepada Bapak Dr. Tukul Rameyo Adi sebagai Kepala Pusat Penelitian Sosial Ekonomi Kelautan dan Perikanan, serta para pihak yang telah berkontribusi dalam penerbitan tulisan ini.

\section{DAFTAR PUSTAKA}

Badan Pusat Statistik Kayong Utara. 2015. Kayong Utara Dalam Angka 2014. Badan Pusat Statistik Kayong Utara. 2015. Indikator Ekonomi Kabupaten Kayong Utara.

David, Meredith E. Forest R. David. Fred R. David. 2009. The Quantitative Strategic Planning Matrix (QSPM) Applied To A Retail Computer Store. The Coastal Business Journal. Spring 2009: Volume 8, Number 1.

Ghosiyan, Asghar. Ebadi, Mahsa. Shojazadeh, Asma. 2015. The Quantitative Strategic Planning Matrix (QSPM) Applied To Sport in West Azerbaijan Province. International Journal of Sport Studies. Vol., 5 (1), 124-128, 2015. ISSN 2251-7502 (c) 2015; Science Research Publications. Available online at http: www.ijssjournal.com. 
Mahfud, Tuatul. Yogiana Mulyani. 2017. Aplikasi Metode QSPM (Quantitative Strategic Planning Matrix) Studi Kasus: Strategi Peningkatan Mutu Lulusan Program Studi Tata Boga. Jurnal Sosial Humaniora Dan Pendidikan Vol. 1 NO.1 ISSN $2580-5398$

Purwandari,Suci.2015. Analisis Quantitative Strategic Planning Matrix (QSPM) SebagaiLandasan Menentukan Strategi Pemasaran Pada Smk Citra MedikaSukoharjo. Jurnal Sainstech Politeknik Indonusa Surakarta ISSN : 2355-5009 Vol. 1 Nomor 3 Tahun 2015.

Puspitasari, Nia Budi. Rumita,Rani. Pratama, Gilang Yuda. 2013. Pemilihan Strategi Bisnis Dengan Menggunakan QSPM (Quantitative Strategic Planning Matrix) Dan Model Maut (Multi Attribute Utility Theory)Studi Kasus Pada Sentra Industri Gerabah Kasongan, Bantul, Yogyakarta. J@TI Undip, Vol VIII, No 3, September 2013.

Rangkuti, F. 2002. Analisis SWOT: Teknik Membedah Kasus Bisnis. Reorientasi Konsep Perencanaan Strategis untuk Menghadapi Abad 21. Penerbit Gramedia Pustaka Utama, Jakarta.
Rencana Pembangunan Jangka Panjang Daerah (RPJPD) Kabupaten Kayong Utara Tahun 2008 - 2025. Peraturan Daerah Kabupaten Kayong Utara Nomor 5 Tahun 2009. Lembaran Daerah Kabupaten Kayong Utara Tahun 2009 Nomor 23.

Setyorini, H., M. Effendi dan I. Santoso. 2016. Analisis Strategi Pemasaran Menggunakan Matriks SWOT dan QSPM (Studi Kasus: Restoran WS Soekarno Hatta Malang). Industria: Jurnal Teknologi dan Manajemen Agroindustri Volume 5 Nomor 1: 46-53. ISSN 2252-7877 (Print) ISSN 2549-3892 (Online). Tersedia online di http:// www.industria.ub.ac.id.

Zulkarnaen, H. O. dan Sutopo. 2013. Analisis Strategi Pemasaran Pada Usaha Kecil Menengah (Ukm) Makanan Ringan (Studi Penelitian UKM Snack Barokah di Solo ). Diponegoro Journal Of Management Volume 2, Nomor 3, Tahun 2013, Halaman 1 http://ejournal-s1.undip.ac.id/index. php/dbr ISSN (Online): 2337-3792. 